\title{
USING DISCRETE CHOICE EXPERIMENTS TO INVESTIGATE SUBJECT PREFERENCES FOR PREVENTIVE ASTHMA MEDICATION
}

\begin{tabular}{|c|c|}
\hline Journal: & Respirology \\
\hline Manuscript ID: & RES-06-269 \\
\hline Manuscript Type: & Original Article \\
\hline $\begin{array}{r}\text { Date Submitted by the } \\
\text { Author: }\end{array}$ & 08-Jun-2006 \\
\hline Complete List of Authors: & $\begin{array}{l}\text { Lancsar, Emily; Cooperative Research Centre for Asthma, University } \\
\text { of Sydney; University of Newcastle upon Tyne, Business School } \\
\text { (Economics) and Centre for Health Service Research } \\
\text { Hall, Jane; Cooperative Research Centre for Asthma, University of } \\
\text { Sydney; University of Technology Sydney, Centre for Health } \\
\text { Economics Research and Evaluation } \\
\text { King, Madeline; Cooperative Research Centre for Asthma, } \\
\text { University of Sydney; University of Technology Sydney, Centre for } \\
\text { Health Economics Research and Evaluation } \\
\text { Kenny, Patsy; Cooperative Research Centre for Asthma, University } \\
\text { of Sydney; University of Technology Sydney, Centre for Health } \\
\text { Economics Research and Evaluation } \\
\text { Louviere, Jordan; Cooperative Research Centre for Asthma, } \\
\text { University of Sydney; University of Technology Sydney, School of } \\
\text { Marketing; University of Technology Sydney, Centre for Health } \\
\text { Economics Research and Evaluation } \\
\text { Fiebig, Denzil; Cooperative Research Centre for Asthma, University } \\
\text { of Sydney; University of Technology Sydney, Centre for Health } \\
\text { Economics Research and Evaluation; University of New South } \\
\text { Wales, School of Economics } \\
\text { Hossain, Ishrat; Cooperative Research Centre for Asthma, } \\
\text { University of Sydney; University of Technology Sydney, Centre for } \\
\text { Health Economics Research and Evaluation } \\
\text { Thien, Frances; Cooperative Research Centre for Asthma, University } \\
\text { of Sydney; The Alfred Hospital, Dept of Allergy, Immunology \& } \\
\text { Respirology Medicine } \\
\text { Reddel, Helen; Cooperative Research Centre for Asthma, University } \\
\text { of Sydney; Woolcock Institute of Medical Research } \\
\text { Jenkins, Christine; Cooperative Research Centre for Asthma, } \\
\text { University of Sydney; Woolcock Institute of Medical Research }\end{array}$ \\
\hline Keywords: & Asthma \\
\hline
\end{tabular}




\section{Manuscript Central ${ }^{\text {Th}}$}




\section{USING DISCRETE CHOICE EXPERIMENTS TO INVESTIGATE SUBJECT PREFERENCES FOR PREVENTIVE ASTHMA MEDICATION}

Emily J. Lancsar ${ }^{1,2,5}$

Jane P. Hall ${ }^{1,2}$

Madeleine King ${ }^{1,2}$

Patsy Kenny ${ }^{1,2}$

Jordan J. Louviere ${ }^{1,2,3}$

Denzil G. Fiebig ${ }^{1,2,4}$

Ishrat Hossain ${ }^{1,2}$

Francis CK Thien ${ }^{1,6}$

Helen K. Reddel ${ }^{1,7}$

Christine R. Jenkins ${ }^{1,7}$

${ }^{1}$ Cooperative Research Centre for Asthma, University of Sydney, NSW 2006,

Australia

${ }^{2}$ Centre for Health Economics Research and Evaluation, University of Technology, Sydney, NSW 2007, Australia

${ }^{3}$ School of Marketing, University of Technology, Sydney NSW 2007, Australia

${ }^{4}$ School of Economics, University of New South Wales, Sydney, NSW 2052, Australia

${ }^{5}$ Current address : Business School (Economics) and Centre for Health Service Research, University of Newcastle upon Tyne, United Kingdom

${ }^{6}$ Dept of Allergy, Immunology \& Respiratory Medicine, The Alfred Hospital, and Monash University, Melbourne, Victoria 3004, Australia

${ }^{7}$ Woolcock Institute of Medical Research, Camperdown, NSW 2050 Australia 


\section{CORRESPONDING AUTHOR}

Emily Lancsar

Business School - Economics and Centre for Health Service Research

University of Newcastle upon Tyne

Level 3, Ridley Building

Claremont Road

Newcastle upon Tyne, NE1 7RU

AUSTRALIA

Email : Emily.Lancsar@ncl.ac.uk

Phone : $+44(0) 1912228646$

Fax : $+44(0) 1912226039$ 


\begin{abstract}
Objective and background: Longterm adherence to inhaled corticosteroids is poor despite the crucial role of preventer medications in achieving good asthma outcomes. This study was undertaken to explore patient preferences in relation to their current inhaled corticosteroid medication, a hypothetical preventer or no medication
\end{abstract} Methodology: A discrete choice experiment (DCE) was conducted in 57 adults with mild-moderate asthma and airway hyperresponsiveness, who were using inhaled corticosteroid $\leq 500 \mu \mathrm{g} /$ day (beclomethasone equivalent). In the DCE, subjects evaluated 16 hypothetical scenarios made up of ten attributes that described the process and outcomes of taking asthma medication, with 2-4 levels for each attribute. For each scenario, subjects chose between the hypothetical medication, the medication they were currently taking and no asthma medication. A random parameter multinomial logit model was estimated to quantify subject preferences for the aspects of taking asthma medication and the influence of attributes on medication decisions. Results: Subjects consistently made choices in favour of being able to do strenuous and sporting activities with or without reliever, experiencing no side effects and never having to monitor their peak flow. Frequency of collecting prescriptions, frequency of taking the medication, its route of administration, and the strength of the doctor recommendation about the medication were not significant determinants of choice. Conclusions: The results of this study suggest that patients prefer a preventer which confers capacity to maximize physical activity, has no side effects and does not require daily peak flow monitoring.

Keywords: patient preferences, asthma

Short title: Subject preferences for preventive asthma medication 


\section{INTRODUCTION}

Asthma patients' willingness to comply with treatments prescribed by their physician plays a critical role in their management. ${ }^{1-3}$ Anecdotal evidence suggests that patients' preference may be influenced by many factors in addition to clinical measures of effectiveness generally considered to be important by physicians. ${ }^{4}$ In view of this, information on patients' preferences for different medications and the aspects of taking medication they do or do not like could be used by physicians when making prescribing decisions. This information may contribute to improved adherence with medication use and may also be of use when designing new medications.

The investigation of individuals' preferences, using stated preferences elicited in response to hypothetical choices under controlled experimental conditions, is well established in marketing research, transport and environmental economics. ${ }^{5}$ These techniques have increasingly been used to study patient preferences across health programs. ${ }^{67}$ To date, this approach has been used to explore preferences for different types of asthma symptoms ${ }^{8}$, characteristics of service delivery for asthma care ${ }^{9}$, the impact of the speed and duration of action of medication for asthma ${ }^{10}$ and the personal impact of exacerbations of COPD. ${ }^{11}$ The earlier studies used pairwise comparisons while in the Johannson study, alternative treatments were ranked. Neither of these approaches allows patients to compare the offered treatment with no treatment, yet the extent of non-adherence to medication regimens suggests that in many cases patients prefer taking no medication to the treatment prescribed.

The aim of this study was to assess preferences for asthma medications by patients who were currently using an inhaled corticosteroid as their preventer. This discrete 
choice experiment extended the work of the above studies by considering a broader range of the effects of medication, including symptom relief, side-effects, convenience and cost. Further, it allowed participants to opt-out of the forced choice between two alternatives by including a "no medication" alternative. We investigated how patients make trade-offs across different attributes, and we modelled the changes in the probability of choosing medication as the attributes changed. We were also interested in the value patients place on different attributes and so we modelled the implied willingness to pay for aspects of asthma medication.

\section{METHODS}

\section{Subjects}

This discrete choice experiment (DCE) was carried out at the commencement of a multicentre, randomised controlled trial of three preventive asthma medications as reported elsewhere. ${ }^{12}$ The trial was conducted in Sydney and Melbourne, Australia, between February 2001 and August 2002. The protocol for the study, including the DCE component, was approved by the ethics review committee for each site, and all subjects provided written informed consent. The trial subjects were aged 16-74 years, and had mild-moderate airway obstruction and hyperresponsiveness to methacholine and symptomatic asthma. Subjects were excluded from screening if they had significant other lung disease, were current smokers or had a smoking history of $\geq 10$ pack years, a history of severe asthma or a recent exacerbation. This paper reports results for subjects who were using inhaled corticosteroids at screening, not more than $500 \mu \mathrm{g} /$ day (beclomethasone equivalent). Screened subjects who were not taking regular preventer medications were excluded from the present analysis. 


\section{Data collection}

Subjects completed a self-administered questionnaire at the screening visit before they underwent any study procedures or received any feedback about their asthma from study staff. The questionnaire comprised demographic questions, a "report card" (questions about respondents' current medication which related to the attributes and levels used in the DCE), and a set of DCE scenarios. The latter generated the preference data by presenting respondents with a series of hypothetical scenarios, with attribute levels varying systematically according to an experimental design. The rationale for this approach was that any product or program can be described in terms of its underlying characteristics or attributes, and individuals' preferences for these attributes can be inferred by observing their choices as the attribute levels vary. In this study, respondents were presented with a hypothetical medication, described in terms of its underlying attributes, and chose among three alternatives: 1) their current medication; 2) the medication described in the hypothetical scenario; and 3) no preventive medication. An example of a scenario and choice question, together with the instructions for completion, are contained in Appendix 1.

\section{Development of the attributes and experimental design}

Attributes and levels associated with the choice of asthma medication were identified from the literature and discussions with respiratory physicians. A series of structured interviews with asthmatic patients attending a respiratory clinic identified missing attributes and the importance of those selected. The preliminary list of attributes and the questionnaire were then pilot tested. From this, ten attributes, seven with four levels and three with two levels, were included in the final design. These attributes and their levels are shown in Table 1. 
Although each respondent could complete a number of scenarios, with this number of attribute/levels (combinations of attribute levels; in this case 131,072), it was necessary to use a fractional factorial design. We selected 256 scenarios which included all levels of all attributes, with pharmacologically implausible combinations of attributes excluded. The resulting design was nearly orthogonal and balanced in terms of the number of times each level of an attribute was seen. The 256 scenarios were divided randomly into 16 versions of the questionnaire, each including 16 scenarios, and subjects were randomly assigned to a version for completion. Pilot testing suggested respondents understood the material presented and were able to complete the questionnaire without difficulty or assistance.

\section{Analysis}

The results were analysed using the random parameter multinomial or mixed logit (MXL) model similar to the method and specification of Hall et al ${ }^{13}$, with some notable exceptions. First, in this study we used information about each participant's current medication (as per the report card) as part of the model estimation. Second, only the intercepts were assumed to be random due to the limitation of the sample size in this study; a larger sample size would have allowed estimation of random attribute parameters as well. Further detail about the econometric analysis is given in the appendix two.

The model results were used to estimate the effect of changes in attribute levels on the probability of patients choosing a particular treatment alternative. To do this, we defined a base case and then systematically changed attribute levels. With this model, the alternative specific intercepts by themselves represent a natural base as they correspond to an average case. This interpretation derives from setting the cost and 
trips to chemist attributes of both current and hypothetical medication to their average level values in the experimental design and from using effects coding for the remaining attributes. For cost we simulated the effect of a $\$ 30$ reduction in cost for a three month supply and for trips to the chemist over a six month period we simulated an increase of one trip. All other attributes had distinct levels and were simulated as such.

\section{Table 1: Attributes and levels of the discrete choice experiment and report card}

The model results were also used to estimate the value patients attach to individual attributes by calculating the compensating variation (referred to more generally as willingness to pay (WTP)) for improvements in each attribute ${ }^{14}$. This involved estimating the WTP for a move from one level of an attribute to another level of the same attribute. Further detail about the method of WTP simulation is provided in the appendix two.

\section{RESULTS}

\section{Subject characteristics}

Fifty seven subjects (27 female, 30 male) were eligible for this analysis. These subjects had an average age of 43 years (range 16-74 years) and a median family income of \$50,001AUD-\$60,000. Mean $\mathrm{FEV}_{1}$ at entry was $82.6 \%$ predicted $(95 \%$ confidence interval $78.8-86.5 \%$ ). Their responses to the report card questions, describing their current medication, are given in the last column of Table 1. Approximately equal numbers of participants stated they were using their preventer medication once or twice a day, and almost one third reported experiencing occasional hoarseness of speech. Most participants could carry out any sporting or strenuous 
activity that they wanted, either with (58\%) or without (23\%) the use of a reliever.

Fifty five subjects responded to all 16 scenarios, and a further two subjects missed one scenario each, giving a total of 910 observations. Of these, "current medication" was chosen for $80 \%$ of scenarios; "hypothetical medication" was chosen for $13 \%$; and "no medication" was chosen for $6 \%$. There were 11 respondents $(19 \%)$ who chose their current medication for all 16 scenarios. These respondents were not excluded from the analysis since they can be accommodated within random utility theory [7].

\section{Analysis of the Preference Data}

The results of the mixed logit model with generic attributes and two random intercepts are presented in Table 2. A number of the attribute coefficients were statistically significantly different from zero and their sign and size were as expected. These are the attributes that are likely to be relevant to subjects when making decisions between asthma medications: cost, symptoms, side effects, daily activities, sporting activities and monitoring peak flow. Increasing cost, reduced participation in sports, restriction to only a few usual daily activities despite taking reliever, and frequent night waking because of asthma each reduced the likelihood that the subject would choose the hypothetical medication. When choosing between medications, subjects preferred not to have to monitor their peak-flow. The occurrence of side-effects was also a significant attribute, with participants being significantly less likely to choose a medication associated with tremors, palpitations, nervousness, headache or oral thrush. Occasional hoarseness of speech was the side effect that affected choice the least, seen best by referring to table 3 , showing the relative impact of different side effects. A hypothetical medication would be more likely to be chosen if occasional hoarseness occurred than if tremors or Candida were side effects. In summary, subjects 
consistently made choices in favour of being able to do strenuous and sporting activities, having no restriction on normal activities, no night waking, experiencing no side effects and never having to monitor their peak flow.

\title{
Table 2: Estimated Mixed Logit model
}

\begin{abstract}
Most of the attributes associated with convenience, that is, frequency of collecting prescriptions, frequency of taking the medication and the route of administration of the medication (tablet or inhaler), were not significant determinants of choice. Similarly, the strength of the doctor recommendation about the medication was also not significant.
\end{abstract}

The coefficients of the random intercepts in the mixed logit measure the inherent preferences of the respondents for taking medication. The common medication intercept (preference for taking either current or hypothetical over no medication) has neither the mean nor standard deviation significantly different from zero. In contrast, the current medication intercept (preference for taking current medication over hypothetical) was significantly greater than zero, and its standard deviation was also significant and large relative to the mean.

\section{Simulated probabilities of choosing medication alternatives}

Respondents displayed a clear preference for their current medication, as reflected in the simulated base case (Table 3 ). The probability of choosing the current medication base case was 0.56 , and it was 0.35 for the hypothetical base case. Since the attribute levels of the current medication and hypothetical base cases were both set to the 
average values in the experimental design, the difference between their predicted probabilities reflect an inherent preference for current treatment, or the status quo. We note that the preference for current medication in the simulations (with a predicted probability of 0.56 ) was considerably less than the rate observed in the choice experiment, where current medication was chosen in $80 \%$ of 910 scenarios. This is because the simulated current medication base (which was at the experimental design average) was less attractive than the average of the patients' actual current medications (as described in the report card).

\section{Table 3: Effect of attributes on the predicted probabilities of choosing each medication alternative}

Table 3 also shows the effects of attributes on the predicted probability of choosing each medication alternative. For example, when assuming the hypothetical medication causes no side effects, this medication becomes more attractive to respondents and the probability of choosing the hypothetical medication increases from the base level of 0.35 to 0.58 . The current medication attributes are still at their base (average) level of side-effects, making the current medication less attractive than the hypothetical medication, and the probability of choosing current medication falls from 0.56 to 0.34. The attributes which had the greatest effect on choice probabilities were sideeffects, symptoms and activities.

The probability of choosing no medication when both the current and hypothetical medications were set to the base case was $9 \%$, not dissimilar to the opt-out rate in the preferences data $(6 \%)$. Further, this did not vary much as attributed levels of the 
hypothetical medication were varied; most of the shift in preferences was between current and hypothetical medications in these simulations.

\section{Simulated willingness to pay}

The WTP for improvements in individual attributes are presented in Table 4 and relate to a three month prescription. The WTP to improve participation in sporting and strenuous activities from reliever being necessary to being able to participate in all activities without difficulty was $\$ 39.82$. Improving symptoms from having exerciserelated breathlessness, cough or wheeze once a week to minimal symptoms once a week or less had a WTP of $\$ 52.57$. Table 4 shows that WTP to eliminate two of the side effects (tremors, palpitations, nervousness or headache and oral thrush) is relatively high. Moving from all daily activities with reliever to all without had a small WTP.

\section{Table 4: Willingness to pay (WTP) for a three month period for improvements in individual attributes}

\section{DISCUSSION}

Our results confirm and extend the findings of other patient preference studies, using DCE and other models, indicating that patients value particular characteristics conferred by preventer medications. These include the ability to participate in strenuous activity, have no restriction of daily activities, have no night waking and be free of side effects. The results from this DCE are clinically plausible, and should inform clinicians about patient priorities that might assist with adherence and appeal to a rational understanding of the cost-benefit of preventer medication for asthma. 
Several aspects of asthma treatment identified as important by patients in this study, such as effectiveness of treatment and freedom from side effects have also been identified in studies which have not employed DCE ${ }^{15-17}$ as well as those that have.$^{810}$ These results are not surprising, but the knowledge should assist physicians when advocating preventer medications to patients, as highlighting these benefits is likely to help patients adhere to treatment.

In this study, patients demonstrated a strong tendency to choose the current medication, a status quo effect also noted by other studies, but not universally so. ${ }^{10}$ On average, the hypothetical medications were less desirable than the current medication (as reported in the report card), a significant observation in that subjects were only eligible if they were currently taking inhaled corticosteroids as preventer medication. However, the average number of repeats (usually a month's supply) which were collected in a 6 month period (2.2) and the average cost for 3 months suggests a high level of non-compliance with their prescribed medication by these subjects. This may be a result of an inevitable 'disconnect' between adherence in theory and practice, where despite good intentions, patients still fail to take inhaled corticosteroids as prescribed.

The coefficients of the random intercepts in the mixed logit have an interesting interpretation. The results on the common medication intercept indicate that medication (whether current or hypothetical) was not valued over no medication per se. In contrast, the current medication intercept (mean significantly greater than zero, and significant and large standard deviation) implies that while, on average, respondents preferred current medication over the hypothetical medication, there was 
substantial variation among individuals and some individuals may have preferred the hypothetical medication.

In addition to clinical relevance of this study there are several methodological strengths of the DCE design we used. First, we provided three alternative choices, allowing an opt-out or no medication option. Interestingly, this was chosen in only a minority of scenarios $(6 \%)$, perhaps reflecting the inclusion and exclusion criteria for this sample (all subjects regularly used preventer medication). Second, we used a report card to record information about each subject's usual preventer medication. This information was used in the model estimation, so the coefficient estimates reflect patients' preferences relative to their status quo. Third, we made the model coefficient estimates more interpretable by converting them into choice probabilities which embody the relative importance patients place on issues such as symptoms and side-effects.

Simulation of WTP is another approach to illustrate the tradeoffs patients were prepared to make across attributes and provide a measure of the monetary value patients attach to individual attributes and there were no unexpected findings. Johansson et al found estimates of WTP that were either similar to actual treatment costs or higher, suggesting patients have a realistic notion of the relative "dollar" value of positive treatment attributes. In the current study, we used treatment costs in the range of $\$ 0$ to $\$ 100$, compared to the average cost of $\$ 25$ per 3 month period experienced by patients in the study. Our estimates of WTP indicated participants were willing to pay $\$ 40$ to $\$ 50$ to reduce symptoms to minimal, and $\$ 20$ to $\$ 60$ (depending on symptom level) to increase their participation in all activities. It is 
noteworthy that patients were willing to pay very large sums for freedom from side effects, namely $\$ 190$ for no tremor and $\$ 135$ for no oral thrush. Interestingly, the change from all activities with reliever to none with reliever was regarded as having low value, suggesting patients are accustomed to using reliever and do not necessarily regard its absence as a high priority in their management goals.

At first sight the finding of a positive coefficient for occasional hoarseness may be surprising. However, this is relative to the other side effect options. The results suggest that the patients in this study regarded this symptom as the least unpleasant amongst the symptoms offered in the scenarios - apart from no side effects, the possible responses included tremors, palpitations, nervousness or headache, oral thrush, or occasional hoarseness of speech. In other studies of patient preferences, side effects were rated as very important, particularly the adverse effects of inhaled corticosteroids. ${ }^{18} 19$ Given the low adherence rates reported in many countries with inhaled corticosteroids ${ }^{20}$, this appears to be a real issue limiting the potential gains to be made by compliance with preventer medications.

The study sample size was relatively small, however a key advantage of the DCE method is its efficiency. Several of the attributes were statistically significant; highlighting that lack of power was not a concern. Further, all discrete choice surveys have to strike a balance between comprehensiveness of attribute descriptions and respondent burden and pilot testing reflected favourably on this balance.

The study was limited to mild-moderate asthmatics who volunteered for a clinical trial. Their reported expenditure on medications and baseline quality of life results suggest that asthma did not have a major impact on their lives. Consequently, these Editorial Office: respirol@aari.uwa.edu.au \&\#9674; Editor-in-Chief: Prof Philip Thompson 
respondents may not be representative of asthmatics more broadly, and this may limit the generalisability of the findings. Although the survey design elicited multiple responses from each individual, the small sample size meant we were not able to fully explore heterogeneity in preferences across individuals. Nevertheless, the results provide valuable information for designing treatment plans and predicting who will comply.

This study makes an important contribution to the literature about patient preferences for preventive asthma medications and the relative importance they place on a wide range of treatment outcomes, both positive and negative. By developing the scenarios and options through patient and clinician interviews, we were able to incorporate clinically important factors that both patients and clinicians indicated were likely to affect treatment choice and compliance. The scenarios focused on a wide range of medication attributes that have direct relevance to patient quality of life [12], and the results of the study should inform clinical decision making and assist in effective communication with patients. The benefits of shared decision making can be enhanced by clinician awareness of patient priorities ${ }^{21}$, and the results from this study offer further information to help clinicians achieve better asthma outcomes in partnership with patients.

\section{$\underline{\text { ACKNOWLEDGEMENTS }}$}

This study was fully supported by a collaborative Industry and Commonwealth Government research initiative, the Cooperative Research Centre for Asthma.

\section{REFERENCES}

Editorial Office: respirol@aari.uwa.edu.au \&\#9674; Editor-in-Chief: Prof Philip Thompson 
1. Blaiss MS. Pharmacoeconomics of asthma. Allergy \& Clinical Immunology International 2003; 15: 240-245.

2. Kievit P, Sculpher M, Williams A. Understanding the patient's perspective of asthma control. Eur Respir Rev 2004; 13: 110-112.

3. Partridge MR, Hill SR. Enhancing care for people with asthma: the role of communication, education, training and self-management Eur Respir J 2000; 16: 333 348.

4. Hyland ME, Stahl E. Asthma treatment needs: a comparison of patients' and health care professionals' perceptions. Clin Ther 2004; 26: 2141-52.

5. Louviere JJ, Hensher DA, Swait JD. Stated choice methods: analysis and applications. Cambridge University Press: Cambridge, U.K, 2000.

6. Ryan M, Farrar S. Using conjoint analysis to elicit preferences for health care. BMJ 2000; 320: 1530-1533.

7. Viney R, Lancsar E, Louviere J. Discrete choice experiments to measure consumer preferences for health and healthcare. Expert Review of Pharmacoeconomics \& Outcomes Research 2002; 2: 319-326.

8. Osman LM, McKenzie L, Cairns J, Friend JA, Godden DJ, Legge JS, et al. Patient weighting of importance of asthma symptoms. Thorax 2001; 56: 138-42.

9. Ratcliffe J, Van Haselen R, Buxton M, Hardy K, Colehan J, Partridge M. Assessing patients' preferences for characteristics associated with homeopathic and conventional treatment of asthma: a conjoint analysis study. Thorax 2002; 57: 503-8.

10. Johansson G, Stallberg B, Tornling G, Andersson S, Karlsson GS, Falt K, et al. Asthma treatment preference study: a conjoint analysis of preferred drug treatments. Chest 2004; 125: 916-923. 
11. Haughney J, Partridge MR, Vogelmeier C, Larsson T, Kessler R, Stahl E, et al. Exacerbations of COPD: quantifying the patient's pespective using discrete choice modelling. Eur Respir J 2005; 26: 623-9.

12. Jenkins C, Thien K, Weatley J, Reddel H. Traditional and patient-centred outcomes with three classes of asthma medication. Eur Respir J 2005; 26: 36-44. 13. Hall J, Fiebig DG, King MT, Hossain I, Louviere JJ. What influences participation in genetic carrier testing? Results from a discrete choice experiment. $J$ Health Econ 2006, 25(3), 520-537.

14. Lancsar E, Savage E. Deriving welfare measures from discrete choice experiments: inconsistency between current methods and random utility and welfare theory. Health Econ 2004; 13: 901-907.

15. Markson LE, Vollmer WM, Fitterman L, O'Connor E, Narayanan S, Berber M, et al. Insight into patient dissatisfaction with asthma treatment. Arch Intern Med 2001; 161: $379-384$.

16. Campbell JL, Keibert GM, Partridge MR. Development of the satisfaction with asthma treatment questionnaire. Eur Respir J 2003; 22: 127-134.

17. Gilleson A, Lecheler J. Bronchial Asthma: a comparison of the doctor's assessment and the patient's opinion. Results of the AIRLife questionnaire study Dtsch Med Wochenschr 2004; 129: 484-489.

18. Leickly FE, Wade SL, Crain E, Kruzson-Moran D, Wright EC, Evans R. Self reported adherence, management behaviour and barriers to care after an emergency department visit by inner city children with asthma. Paediatrics 1998; 101: E8. 19. Yoos HL, Kitzman H, McMullen A. Barriers to anti-inflammatory medication use in childhood asthma. Ambulatory Paediatrics 2003; 3: 181-190.

20. Cerveri I, Locatelli F, Zoia MC, Accordini S, de Marco R. International variations in asthma treatment compliance. Eur Respir J 1999; 14: 288-294.

Editorial Office: respirol@aari.uwa.edu.au \&\#9674; Editor-in-Chief: Prof Philip Thompson 
21. Say RE, Thomson R. The importance of patient preferences in treatment decisions - challenges for doctors. BMJ 2003; 327: 542-5.

22. McFadden D. Econometric models of probabilistic choice. In Structural analysis of discrete data with economic applications, Manski CF, McFadden D, (eds). MIT Press: Boston, 1981; 422-434. 
Table 1: Attributes and levels of the discrete choice experiment and report card

\begin{tabular}{|c|c|c|c|}
\hline Attribute & Description & Levels & Report card responses \\
\hline \multicolumn{4}{|c|}{ Process Attributes } \\
\hline $\operatorname{Cost}^{1}$ & $\begin{array}{l}\text { Total cost of the drug to } \\
\text { you for a (3) month } \\
\text { supply is: }\end{array}$ & $\$ 0 ; \$ 20 ; \$ 80 ; \$ 100$ & $\begin{array}{l}\text { Average } \\
\text { cost: \$A25 }\end{array}$ \\
\hline Repeats & $\begin{array}{l}\text { In order to pick up your } \\
\text { prescription and repeats } \\
\text { for each } 6 \text { month period } \\
\text { you will have to go to the } \\
\text { chemist }^{2} \text { : }\end{array}$ & Once; twice; 3 times; 6 times & $\begin{array}{l}\text { Average } \\
\text { repeats: } 2.2\end{array}$ \\
\hline \multirow[t]{4}{*}{ Administration } & \multirow[t]{4}{*}{ You take the drug via: } & - an aerosol inhaler & $54 \%$ \\
\hline & & $\begin{array}{l}\text { - a dry powder inhaler, e.g. Turbuhaler } \\
\text { or Accuhaler }\end{array}$ & $46 \%$ \\
\hline & & - a tablet & $0 \%$ \\
\hline & & - both an inhaler and a tablet & $0 \%$ \\
\hline \multirow[t]{2}{*}{ How often } & \multirow{2}{*}{$\begin{array}{l}\text { You need to take the } \\
\text { drug: }\end{array}$} & - once a day & $53 \%$ \\
\hline & & - $\quad$ twice a day & $46 \%$ \\
\hline \multirow[t]{2}{*}{ Monitoring } & \multirow{2}{*}{$\begin{array}{l}\text { You measure your } \\
\text { morning peak flow: }\end{array}$} & - $\quad$ every morning & $23 \%$ \\
\hline & & - $\quad$ never & $77 \%$ \\
\hline \multicolumn{4}{|c|}{ Health Outcomes } \\
\hline \multirow[t]{4}{*}{$\begin{array}{l}\text { Symptom } \\
\text { Severity }\end{array}$} & \multirow[t]{4}{*}{$\begin{array}{l}\text { On this drug you will } \\
\text { experience: }\end{array}$} & $\begin{array}{l}\text { - minimal symptoms once a week or } \\
\text { less }\end{array}$ & $26 \%$ \\
\hline & & $\begin{array}{l}\text { - exercise breathlessness, cough or } \\
\text { wheeze once a week }\end{array}$ & $35 \%$ \\
\hline & & $\begin{array}{l}\text { - chest tightness doing normal activities } \\
\text { requiring reliever twice a week }\end{array}$ & $26 \%$ \\
\hline & & $\begin{array}{l}\text { - } \text { awaking at night with asthma } \\
\text { requiring the use of reliever more } \\
\text { than } 4 \text { times a week }\end{array}$ & $12 \%$ \\
\hline \multirow[t]{4}{*}{$\begin{array}{l}\text { Usual daily } \\
\text { activities }\end{array}$} & \multirow[t]{4}{*}{$\begin{array}{l}\text { Compared to most people } \\
\text { in your age group you are } \\
\text { able to participate in: }\end{array}$} & $\begin{array}{l}\text { - all usual daily activities without the } \\
\text { use of a reliever }\end{array}$ & $32 \%$ \\
\hline & & $\begin{array}{l}\text { - all usual daily activities provided you } \\
\text { use a reliever for some of these } \\
\text { activities }\end{array}$ & $60 \%$ \\
\hline & & $\begin{array}{l}\text { most usual daily activities provided } \\
\text { you use your reliever most of the time }\end{array}$ & $7 \%$ \\
\hline & & $\begin{array}{l}\text { a few usual daily activities provided } \\
\text { you use a reliever all the time }\end{array}$ & $2 \%$ \\
\hline
\end{tabular}


Table 1 continued

\begin{tabular}{|c|c|c|c|}
\hline \multirow[t]{4}{*}{$\begin{array}{l}\text { Sporting/strenuous } \\
\text { activities }\end{array}$} & \multirow[t]{4}{*}{$\begin{array}{l}\text { You are able to } \\
\text { participate in: }\end{array}$} & $\begin{array}{l}\text { all the sporting or strenuous activity } \\
\text { you want without difficulty }\end{array}$ & $23 \%$ \\
\hline & & $\begin{array}{l}\text { all the sporting or strenuous activity } \\
\text { you want with the use of reliever }\end{array}$ & $58 \%$ \\
\hline & & $\begin{array}{l}\text { - a restricted range of the sporting and } \\
\text { strenuous activity you want with the } \\
\text { use of a reliever }\end{array}$ & $16 \%$ \\
\hline & & $\begin{array}{l}\text { - no sporting or other strenuous } \\
\text { activity }\end{array}$ & $4 \%$ \\
\hline \multirow[t]{4}{*}{ Side effects } & \multirow{4}{*}{$\begin{array}{l}\text { On this drug you } \\
\text { will experience: }\end{array}$} & - $\quad$ no side effects & $56 \%$ \\
\hline & & $\begin{array}{l}\text { tremors, palpitations, nervousness } \\
\text { or headache }\end{array}$ & $3 \%$ \\
\hline & & - $\quad$ oral thrush & $11 \%$ \\
\hline & & - occasional hoarseness of speech & $30 \%$ \\
\hline \multicolumn{4}{|l|}{ Inputs } \\
\hline \multirow[t]{2}{*}{ Dr recommendation } & \multirow{2}{*}{$\begin{array}{l}\text { Your doctor says } \\
\text { that this drug: }\end{array}$} & - is the best for your asthma & $28 \%$ \\
\hline & & $\begin{array}{l}\text { - will give you satisfactory control of } \\
\text { your asthma }\end{array}$ & $72 \%$ \\
\hline
\end{tabular}

${ }^{1}$ Amounts are quoted in Australian dollars (\$AUS) ), the report card question asked how much subjects currently paid for a 3 month supply of preventer medication and did not constrain responses to the levels used on the cost attribute in the DCE.

2 "Chemist" = pharmacist or drug store 
Table 2: Estimated Mixed Logit model

\begin{tabular}{|c|c|c|c|}
\hline Variables & Description & Coefficients & $\begin{array}{l}\text { Standard } \\
\text { error }\end{array}$ \\
\hline \multirow[t]{2}{*}{ Common medication intercept } & Mean & 11.53 & 7.75 \\
\hline & Standard Deviation & 9.05 & 5.61 \\
\hline \multirow[t]{2}{*}{ Current medication intercept } & Mean & $0.73 *$ & 0.39 \\
\hline & Standard Deviation & $1.96 * * *$ & 0.38 \\
\hline Cost & & $-0.015^{* * *}$ & 0.005 \\
\hline Trips to the chemist & & 0.059 & 0.086 \\
\hline \multirow[t]{4}{*}{ Administration } & Aerosol inhaler & 0.26 & 0.18 \\
\hline & Powder inhaler & 0.11 & 0.25 \\
\hline & Tablet & -0.0031 & 0.20 \\
\hline & Inhaler \& tablet & $-0.37^{*}$ & 0.21 \\
\hline \multirow[t]{2}{*}{ Frequency of taking the drug } & Once per day & 0.11 & 0.16 \\
\hline & Twice per day & -0.11 & 0.16 \\
\hline \multirow[t]{4}{*}{ Symptoms } & Minimal & $1.23 * * *$ & 0.27 \\
\hline & Cough, wheeze, etc. & $0.36^{*}$ & 0.21 \\
\hline & Chest tightness & $-0.34 *$ & 0.18 \\
\hline & Waking at night & $-1.25 * * *$ & 0.23 \\
\hline \multirow[t]{2}{*}{ Dr Recommendation } & Best for your asthma & -0.011 & 0.12 \\
\hline & Satisfactory control & 0.011 & 0.12 \\
\hline \multirow[t]{4}{*}{ Usual daily activities } & All without reliever & $0.43^{*}$ & 0.23 \\
\hline & All with reliever & $0.47 *$ & 0.25 \\
\hline & Most with reliever & 0.081 & 0.24 \\
\hline & Few with reliever & $-0.98 * * *$ & 0.24 \\
\hline \multirow[t]{4}{*}{ Sporting/strenuous activities } & All without difficulty & $1.41 * * *$ & 0.26 \\
\hline & All with reliever & $0.76^{* * *}$ & 0.24 \\
\hline & Restricted with reliever & $-0.61 * *$ & 0.27 \\
\hline & None & $-1.56 * * *$ & 0.26 \\
\hline \multirow[t]{2}{*}{ Monitoring peak flow } & Every morning & $-0.29 * *$ & 0.14 \\
\hline & Never & $0.29 * *$ & 0.14 \\
\hline \multirow[t]{4}{*}{ Side effects } & None & $1.58 * * *$ & 0.29 \\
\hline & Tremors, etc. & $-1.67 * * *$ & 0.47 \\
\hline & Oral thrush & $-0.67 * *$ & 0.32 \\
\hline & $\begin{array}{l}\text { Occasional hoarseness } \\
\text { of speech }\end{array}$ & $0.76^{* *}$ & 0.37 \\
\hline $\begin{array}{l}\text { Pseudo R2 } \\
\text { Log-Likelihood }\end{array}$ & $\begin{array}{c}0.5007 \\
-281.9074\end{array}$ & & \\
\hline
\end{tabular}

\section{Notes:}

$1 . * *$ Significant at $1 \%$ level; ** Significant at $5 \%$ level; * Significant at $10 \%$ level.

2. Pseudo $\mathrm{R}^{2}\left(\mathrm{McFadden}\right.$ 's $\left.\mathrm{R}^{2}\right)$ is defined as $1-\left(\mathrm{LL} / \mathrm{LL}_{0}\right)$, where $\mathrm{LL}$ is the value of the (simulated) loglikelihood function evaluated at the estimated parameters while $\mathrm{LL}_{0}$ is the value of the log-likelihood function for a base model that only contains a non-random alternative-specific intercepts.

3. In the estimation, Cost and trips to the chemist are continuous and mean centered; other attributes are effects coded [5].

4. A negative sign for a particular attribute level implies that level impacted negatively on utility and therefore reduced the probability of choosing the current or hypothetical medication with that level. In general, the signs of the attributes were as expected. 
Table 3: Effect of attributes on the predicted probabilities of choosing each medication alternative

\begin{tabular}{|c|c|c|c|c|}
\hline & & \multicolumn{3}{|c|}{ Predicted Probability $^{2}$} \\
\hline & & $\begin{array}{l}\text { Current } \\
\text { Medication }\end{array}$ & $\begin{array}{l}\text { Hypothetical } \\
\text { Medication }\end{array}$ & $\begin{array}{l}\text { No } \\
\text { Medication }\end{array}$ \\
\hline \multicolumn{2}{|l|}{ Base probability $^{1}$} & 0.56 & 0.35 & 0.093 \\
\hline Attribute & $\begin{array}{l}\text { Hypothetical set to this } \\
\text { level }\end{array}$ & & & \\
\hline Cost & $\$ 30$ reduction & $0.49 *$ & $0.42 *$ & 0.089 \\
\hline Trips to the chemist & Increase of one visit & 0.55 & 0.36 & 0.092 \\
\hline \multirow[t]{4}{*}{ Administration } & Aerosol inhaler & 0.52 & $0.39 *$ & 0.091 \\
\hline & Powder inhaler & 0.54 & 0.37 & 0.092 \\
\hline & Tablet & 0.56 & 0.35 & 0.093 \\
\hline & Inhaler \& tablet & 0.60 & $0.30 *$ & 0.095 \\
\hline \multirow[t]{2}{*}{$\begin{array}{l}\text { Frequency of taking } \\
\text { the drug }\end{array}$} & Once per day & 0.54 & 0.37 & 0.092 \\
\hline & Twice per day & 0.57 & 0.34 & 0.093 \\
\hline \multirow[t]{4}{*}{ Symptoms } & Minimal & $0.39 * *$ & $0.53 * * *$ & $0.082^{*}$ \\
\hline & Cough, wheeze, etc. & 0.51 & $0.40 *$ & 0.090 \\
\hline & Chest tightness & 0.60 & $0.31 *$ & 0.095 \\
\hline & Waking at night & $0.70 * *$ & $0.20 * *$ & 0.100 \\
\hline \multirow[t]{2}{*}{ Dr Recommendation } & Best for your asthma & 0.55 & 0.35 & 0.092 \\
\hline & Satisfactory control & 0.56 & 0.35 & 0.093 \\
\hline \multirow[t]{4}{*}{ Usual daily activities } & All without reliever & $0.50^{*}$ & $0.41 *$ & 0.089 \\
\hline & All with reliever & $0.49 *$ & $0.42 *$ & 0.089 \\
\hline & Most with reliever & 0.54 & 0.36 & 0.092 \\
\hline & Few with reliever & $0.67 * *$ & $0.23 * *$ & 0.099 \\
\hline \multirow[t]{4}{*}{$\begin{array}{l}\text { Sporting/strenuous } \\
\text { activities }\end{array}$} & All without difficulty & $0.36^{* *}$ & $0.56^{* * *}$ & $0.080^{*}$ \\
\hline & All with reliever & $0.45 *$ & $0.46^{* *}$ & 0.086 \\
\hline & Restricted with reliever & $0.63 *$ & $0.27 * *$ & 0.097 \\
\hline & None & $0.73 * *$ & $0.17 * * *$ & $0.102 *$ \\
\hline \multirow[t]{2}{*}{$\begin{array}{l}\text { Monitoring peak } \\
\text { flow }\end{array}$} & Every morning & 0.59 & $0.31 *$ & 0.095 \\
\hline & Never & 0.52 & $0.39 *$ & 0.090 \\
\hline \multirow[t]{4}{*}{ Side effects } & None & $0.34 * *$ & $0.58 * * *$ & $0.078^{*}$ \\
\hline & Tremors, etc. & $0.74 * *$ & $0.16^{* * *}$ & $0.102^{*}$ \\
\hline & Oral thrush & $0.64 *$ & $0.26^{* *}$ & 0.097 \\
\hline & $\begin{array}{l}\text { Occasional hoarseness } \\
\text { of speech }\end{array}$ & $0.45 *$ & $0.46^{* *}$ & 0.086 \\
\hline
\end{tabular}

Notes:

1. The base probability represents the case where all attributes levels were set to the average values in the experimental design.

2. The effect of each attribute level on predicted probabilities is calculated by setting the hypothetical medication to that particular level (see methods for more detail). The degree of change relative to the base is shown: * signifies changes $>10 \%$; $* *$ signifies changes $>20 \%$; $* * *$ signifies changes $>50 \%$. 
Table 4: Willingness to pay (WTP) for a three month period for improvements in individual attributes

\begin{tabular}{|l|l|l|}
\hline Attribute & Improvement in the attribute & $\mathrm{WTP} / 3$ months \\
\hline Monitoring peak flow & Every morning to never & $\$ 35.04$ \\
\hline $\begin{array}{l}\text { Sporting/strenuous } \\
\text { activity }\end{array}$ & None to a restricted range & $\$ 55.94$ \\
\hline & A restricted range to all with reliever & $\$ 81.56$ \\
\hline & $\begin{array}{l}\text { All with reliever to all without } \\
\text { difficulty }\end{array}$ & $\$ 39.82$ \\
\hline Usual daily activities & $\begin{array}{l}\text { Few with reliever to most with } \\
\text { reliever }\end{array}$ & $\$ 62.52$ \\
\hline & $\begin{array}{l}\text { Most with reliever to all with } \\
\text { reliever }\end{array}$ & $\$ 23.32$ \\
\hline & $\begin{array}{l}\text { All with reliever to all without } \\
\text { reliever }\end{array}$ & $\$ 2.68$ \\
\hline Symptoms & Waking at night to chest tightness & $\$ 53.19$ \\
\hline & Chest tightness to cough etc & $\$ 41.77$ \\
\hline & Cough etc to minimal symptoms & $\$ 52.57$ \\
\hline Side effects & Tremors to no side effects & $\$ 193.49$ \\
\hline & Oral thrush to no side effects & $\$ 135.52$ \\
\hline & Hoarseness to no side effects & $\$ 49.55$ \\
\hline
\end{tabular}




\section{APPENDIX 1: Example choice set}

\begin{tabular}{|l|l|}
\hline Total cost of the drug to you for a 3 month & Free \\
supply is: & \\
\hline repeats for each 6 month period you will & \\
have to go to the chemist: & Twice \\
\hline You take the drug via: & a tablet \\
\hline You need to take the drug: & Once a day \\
\hline On this drug you will experience: & Exercise breathlessness, cough or wheeze \\
\hline Your doctor says that this drug: & once a week \\
\hline Compared to most people in your age & all usual daily activities without the use of \\
\hline Youp you are able to participate in: & a reliever \\
\hline You are able to participate in: & all the sporting or strenuous activity you \\
\hline This drug will cause: & wever without difficulty \\
\hline
\end{tabular}

Suppose you had the option of taking the medication described in the situation above. Considering how severe your asthma is, which option would you prefer out of:

$\square_{1} \quad$ Your current preventer medication

$\square_{2} \quad$ The preventer medication in the situation above

$\square_{3} \quad$ No preventer medication 


\section{APPENDIX 2: Online supplement}

\section{USING DISCRETE CHOICE EXPERIMENTS TO INVESTIGATE SUBJECT PREFERENCES FOR PREVENTIVE ASTHMA MEDICATION}

\section{Econometric Analysis}

The statistical analysis of choice data relies on the random utility model ${ }^{22}$, where each respondent faces a choice amongst $J$ alternatives or options repeated under $S$ scenarios or choice situations. The utility that individual $i$ derives from alternative $j$ in scenario $s$ is composed of systematic and random components denoted by

(1) $\quad U_{i s j}=X_{i s j}^{\prime} \beta_{i}+\varepsilon_{i s j}$

where $X_{i s j}$ is a $K \times 1$ vector of explanatory variables and $\beta_{i}$ is a conformable vector of coefficients.

This gives the standard multinomial logit (MNL) specification, conditional on $\beta_{i}$, and assuming the disturbance terms $\varepsilon_{i s j}$ to be identically and independently distributed (IID) as extreme value. The probability that individual $i$ chooses $j$ in scenario $s$ is then given by:

(2) $\quad P_{i s j}=\frac{\exp \left(X_{i s j}^{\prime} \beta_{i}\right)}{\sum_{h} \exp \left(X_{i s h}^{\prime} \beta_{i}\right)}$. 
In general, variability (or heterogeneity) among people is expected. Heterogeneity is a result of the variation in behavior across individuals that can be attributed to their differences in tastes and decision making processes. The MNL specification can be generalized to account for this heterogeneity by allowing components of $\beta$ to vary over individuals but not over the repeated choices made by an individual. The effect of this is to introduce error correlation across choice situations, accounting for the dependence structure in unobserved utility among the repeated choices of an individual that comes from the panel structure of the data. This correlation is not perfect because of the presence of the independent extreme value term $\varepsilon_{i s j}$. This specification also induces correlation across the alternatives in each choice situation as long as generic attributes appear in the utility specifications for these alternatives.

The resultant random parameter or mixed logit (MXL) model used in this analysis is similar to the method and specification of Hall et $a l^{13}$, with some notable exceptions. First, in this study we utilized information about the participant's current medication as part of the model estimation. This information was recorded in a "report card", a set of self-complete questions included in the questionnaire whereby participants described their current medication in terms of the same attributes and levels as in the discrete choice experimental design. Second, in this paper only the intercepts were assumed random due to the limitation of our sample size in this study, while in the study by Hall et al, a larger sample size allowed estimation of random attributes as well.

Estimation by maximum simulated likelihood (MSL) was undertaken using a program 
downloaded from Kenneth Train's website ${ }^{1}$. All estimation results reported in this paper were generated assuming the random parameters were normally distributed and using 1000 Halton draws to simulate the likelihood functions to be maximized ${ }^{24}$.

\section{Simulation of predicted probabilities}

We simulated the impact on probabilities by varying the level of one attribute at a time for the hypothetical medication (note the attribute levels of the current medication were not changed from the base level. Thus we were simulating the impact of a change in desirability of the hypothetical medication (caused by, for example, an increase in its cost or side-effects) on the probability of a participant selecting the hypothetical medication, and consequently the probability of the other two alternatives being selected.

Taking 1000 random draws from the estimated distributions of the random parameters, probabilities were simulated using equation (2) and the reported predictions calculated as means over these 1000 replications.

\section{Simulation of willingness to pay}

The willingness to pay is also referred to as the compensating variation (CV). The $\mathrm{CV}$ associated with moving from an initial state in which the attributes are described by a particular level to another in which one or more of the attribute levels have been improved can be expressed as

\footnotetext{
${ }^{1}$ http://elsa.berkeley.edu/Software/abstracts/train0296.html

Editorial Office: respirol@aari.uwa.edu.au \&\#9674; Editor-in-Chief: Prof Philip Thompson
} 
(3)

$$
C V=\frac{1}{\beta_{p}}\left[\ln \sum_{j=1}^{J} \exp \left(V_{j}^{0}\right)-\ln \sum_{j=1}^{J} \exp \left(V_{j}^{1}\right)\right]
$$

in which $V_{j}^{0}$ and $V_{j}^{1}$ are the estimated value of equation (1) before and after the attribute improvement respectively and the difference in these is weighted by the inverse of the coefficient on the price attribute ${ }^{14}$.

Similar to the simulation of the predicted probabilities, taking 1000 random draws from the estimated distributions of the random parameters, the WTP values were simulated using equation (3) and reported WTP calculated as means over these 1000 replications.

\section{$\underline{\text { References }}$}

13. Hall J, Fiebig DG, King MT, Hossain I, Louviere JJ. What influences participation in genetic carrier testing? Results from a discrete choice experiment. J Health Econ 2006, 25(3), 520-537.

14. Lancsar E, Savage E. Deriving welfare measures from discrete choice experiments: inconsistency between current methods and random utility and welfare theory. Health Econ 2004; 13: 901-907.

22. McFadden D. Econometric models of probabilistic choice. In Structural analysis of discrete data with economic applications, Manski CF, McFadden D, (eds). MIT Press: Boston, 1981; 422-434. 